EXTENDED REPORT

\title{
Investigation of crystallin genes in familial cataract, and report of two disease associated mutations
}

\author{
K P Burdon, M G Wirth, D A Mackey, I M Russell-Eggitt, J E Craig, J E Elder, J L Dickinson, M M Sale
}

Br J Ophthalmol 2004;88:79-83

See end of article for authors' affiliations

....................

Correspondence to: Dr Michèle M Sale, Center for Human Genomics, Wake Forest University School of Medicine, Medical Center Blvd, Winston-Salem NC 27157, USA; msale@wfubmc.edu

Accepted for publication 2 July 2003

\begin{abstract}
Aims: Mutations of seven crystallin genes have been shown to cause familial cataract. The authors aimed to identify disease causing crystallin mutations in paediatric cataract families from south eastern Australia. Methods: 38 families with autosomal dominant or recessive paediatric cataract were examined. Three large families were studied by linkage analysis. Candidate genes at regions providing significant LOD scores were sequenced. Single stranded conformational polymorphism (SSCP) analysis was used to screen five crystallin genes in the probands, followed by direct sequencing of observed electrophoretic shifts. Mutations predicted to affect the coding sequence were subsequently investigated in the entire pedigree. Results: A LOD score of 3.72 was obtained at the $\gamma$-crystallin locus in one pedigree. Sequencing revealed a P23T mutation of CRYGD, found to segregate with disease. A splice site mutation at the first base of intron 3 of the CRYBA I/A3 gene segregating with disease was identified by SSCP in another large family. Five polymorphisms were also detected.

Conclusions: Although mutations in the five crystallin genes comprehensively screened in this study account for $38 \%$ of paediatric cataract mutations in the literature, only two causative mutations were detected in 38 pedigrees, suggesting that crystallin mutations are a relatively rare cause of the cataract phenotype in this population.
\end{abstract}

ongenital or paediatric cataract is a clinically and genetically heterogeneous disorder. The phenotype varies considerably between and within families. ${ }^{1}$ Familial paediatric cataract is most commonly inherited in an autosomal dominant manner, although recessive and $\mathrm{X}$ linked forms also exist. ${ }^{2}$ Mutations in 14 genes have been described in association with the phenotype of isolated paediatric/congenital cataract. These include members of the crystallin and connexin families, ${ }^{3}$ membrane proteins $M I P^{4}$ and LIM2, ${ }^{5}$ a cytoskeletal protein $B F S P 2,{ }^{67}$ and transcription factors PITX $3^{8}$ and HSF4. ${ }^{\circ}$

Mutations in seven crystallin genes have been shown to cause monogenic paediatric cataract. These include $\alpha \mathrm{A}$ crystallin $(C R Y A A),{ }^{10}{ }^{11} \beta \mathrm{Al} / \mathrm{A} 3$-crystallin $(C R Y B A 1 / A 3) .{ }^{12}{ }^{13}$ $\beta \mathrm{B} 2$-crystallin $(C R Y B B 2),{ }^{14}{ }^{15} \gamma \mathrm{C}$-crystallin $(C R Y G C),{ }^{16}{ }^{17}$ and $\gamma \mathrm{D}$-crystallin $(C R Y G D) .{ }^{16}{ }^{18} \alpha \mathrm{B}-(C R Y A B)$ and $\beta \mathrm{Bl}$-crystallin $(C R Y B B 1)$ mutations ${ }^{19} 20$ were reported in familial cataract after the commencement of this study.

While it is apparent that familial cataract is genetically heterogeneous, only 17 families with crystallin mutations have been described. It is unknown whether mutations of these genes are a significant cause of familial cataract. In order to detect causative mutations in our population of 38 familial paediatric cataract pedigrees from south eastern Australia, large pedigrees were assessed by linkage analysis, while the first five reported crystallin genes were screened in smaller pedigrees by single stranded conformational polymorphism (SSCP) analysis.

\section{MATERIALS AND METHODS}

Paediatric cataract families and genetic material

Approval was obtained from the human research ethics committees of the Royal Children's Hospital, Melbourne, the Royal Victorian Eye and Ear Hospital, Melbourne, and the University of Tasmania, Hobart, and informed consent was obtained from all participants or their guardians. Ascertainment and recruitment of pedigrees has been previously described. ${ }^{21}$ All available family members were examined by one or more ophthalmologists (MGW, DAM, JEE, IMR-E, or JEC). Buccal mucosa swabs were collected and DNA extracted using the PureGene DNA Isolation Kit (Gentra Systems).

\section{Primer extension preamplification}

Primer extension preamplification $(\mathrm{PEP})^{22}$ was used to provide sufficient DNA from buccal mucosa swabs for subsequent polymerase chain reaction (PCR) based amplifications. Each $50 \mu \mathrm{l}$ reaction contained 50-100 ng template DNA, 1000 pmol random PolyN 15-mer primer (Operon Technologies), $200 \mu \mathrm{M}$ dNTPs (Promega), $2 \mathrm{mM} \mathrm{Mg}^{2+}$, and 5 U Taq Polymerase (Qiagen). The reactions were amplified over 50 cycles of $92^{\circ} \mathrm{C}$ for 1 minute, $37^{\circ} \mathrm{C}$ for 2 minutes, and $55^{\circ} \mathrm{C}$ for 4 minutes with a final extension of $72^{\circ} \mathrm{C}$ for 10 minutes, and then diluted to $25-50 \mathrm{ng} / \mu \mathrm{l}$ for PCR.

\section{Linkage analysis}

Individuals from three large families were genotyped using fluorescently labelled primers to amplify microsatellite markers (table 1) from each of the five crystallin loci and analysed using an ABI Prism 310 Genetic Analyzer (Applied Biosystems). Primer sequences and PCR conditions are available from the Genome Database (www.gdb.org).

Allele frequencies were calculated from founders in the pedigrees. Two point linkage analysis was carried out with MLINK, part of the FASTLINK package. ${ }^{23}$ Disease gene frequency was set to 0.0001 . Penetrance was set at 0.0 in wild type homozygotes and 0.95 in heterozygotes and mutant homozygotes. LOD scores were calculated over a range of recombination distances between 0 and 0.5 for each marker.

\section{Single stranded conformational polymorphism (SSCP) analysis}

The proband from each pedigree, including those investigated by linkage, was screened for mutations in CRYAA, CRYBAI/A3, $C R Y B B 2, C R Y G C$, and CRYGD by SSCP. CRYAB and CRYBBI had not been associated with cataract at the time of this 
Table 1 LOD scores obtained for crystallin loci genotyped in three large cataract pedigrees

\begin{tabular}{|c|c|c|c|c|c|c|c|c|c|}
\hline Pedigree & Gene & Marker & 0.0 & 0.1 & 0.2 & 0.3 & 0.4 & Max LOD & $\theta$ \\
\hline \multirow[t]{5}{*}{ Crch30 } & CRYGC/GD* & D2S2358 & -8.62 & -3.39 & -1.78 & -0.89 & -0.33 & 0.00 & 0.50 \\
\hline & CRYAB† & D11S1347 & -5.25 & -1.48 & -0.84 & -0.46 & -0.19 & 0.00 & 0.50 \\
\hline & CRYBA1 & D17S841 & 0.10 & 0.08 & 0.07 & 0.05 & 0.02 & 0.10 & 0.00 \\
\hline & CRYAA & D21S1890 & -0.69 & 0.30 & 0.29 & 0.18 & 0.06 & 0.32 & 0.14 \\
\hline & CRYBB 1/BB2* $\dagger$ & D22S926 & -4.10 & -1.23 & -0.64 & -0.35 & -0.15 & 0.00 & 0.50 \\
\hline \multirow[t]{5}{*}{ Crch32 } & CRYGC/GD* & D2S2358 & -20.87 & -3.39 & -1.64 & -0.50 & -0.02 & 0.04 & 0.45 \\
\hline & CRYAB† & D11S1347 & -5.21 & 0.53 & 0.65 & 0.52 & 0.29 & 0.66 & 0.18 \\
\hline & CRYBA1 & D17S841 & -7.33 & -2.00 & -0.72 & -0.14 & 0.06 & 0.07 & 0.42 \\
\hline & CRYAA & D21S1890 & -6.62 & -1.38 & -0.22 & 0.16 & 0.17 & 0.20 & 0.37 \\
\hline & CRYBB 1/BB2* $\dagger$ & D22S926 & -16.44 & -7.70 & -1.11 & -2.05 & -0.78 & 0.00 & 0.50 \\
\hline \multirow[t]{2}{*}{ Ctas 17} & CRYGC/GD* & D2S2358 & 2.94 & 3.61 & 2.89 & 1.88 & 0.80 & 3.72 & 0.06 \\
\hline & CRYBA1 & D17S841 & -11.27 & -4.06 & -2.10 & -1.03 & -0.39 & 0.00 & 0.50 \\
\hline
\end{tabular}

*Two crystallin genes are represented by one microsatellite marker at these loci.

TCRYAB and CRYBBI were not screened by SSCP as they were not reported in the literature at the time of the investigation.

study and were not screened in this way. Both forward and reverse PCR primers (sequences available on request) were end labelled with $\gamma^{32} \mathrm{P}$-ATP by T4 polynucleotide kinase (New England Biolabs). Each exon was amplified by PCR in $10 \mu \mathrm{l}$ reaction volumes containing $0.7 \mu \mathrm{M}$ of each unlabelled primer and $0.11 \mu \mathrm{M}$ of each labelled primer, $200 \mu \mathrm{M}$ dNTPs (Promega), 0.5 U Taq polymerase (Qiagen), and $50 \mathrm{ng}$ of DNA. PCR products were mixed with SSCP Stop Solution (95\% formamide, $10 \mathrm{mM} \mathrm{NaOH}, 0.25 \%$ bromophenol blue, 0.25\% Xylene Cyanol, all reagents from Sigma-Aldrich), denatured at $95^{\circ} \mathrm{C}$ for 2 minutes, and snap cooled on ice. Samples were electrophoresed on $0.4 \mathrm{~mm}, 0.5 \mathrm{X}$ Mutation Detection Enhancement (MDE) Gel (Edwards Instrument Co) at $8 \mathrm{~W}$ for 16 hours at room temperature. Products were visualised on Biomax MR film (Kodak).

\section{DNA sequence analysis}

PCR products were cycle sequenced using Big Dye Terminator Ready Reaction Mix (Applied Biosystems) and an ABI Prism 310 Genetic Analyzer (Applied Biosystems).

\section{Denaturing high performance liquid chromatography (dHPLC)}

Exon 2 of CRYGD was amplified by PCR and injected onto a Varian Helix dHPLC column at $64^{\circ} \mathrm{C}$. The acetonitrile concentration was varied from $45 \%$ to $68 \%$ over 7 minutes. Chromatograms were compared to those generated by samples of known sequence.

\section{Restriction digest}

Exon 3 of CRYBAI/A3 was amplified by PCR in pedigree crch08; $10 \mu \mathrm{l}$ of PCR product were digested with $1 \mathrm{U}$ of NlaIII (New England Biolabs) at $37^{\circ} \mathrm{C}$ for 1 hour. Products were electrophoresed on a $2 \%$ agarose gel and stained with ethidium bromide.

\section{RESULTS}

Thirty eight pedigrees were investigated including 32 with autosomal dominant inheritance, two autosomal recessive pedigrees, and four small families of uncertain inheritance.

\section{Linkage analysis of large pedigrees}

Four large pedigrees were selected for linkage analysis on the basis of simulations using SLINK ${ }^{24} 25$ (data not shown). A crystallin mutation was detected in pedigree crch08 before the linkage study, hence this family was not included in linkage analysis.

LOD scores for the five loci genotyped in the three remaining large pedigrees are presented in table 1 . A significant LOD score of 3.72 was obtained at $\theta=0$ from D2S2358 in pedigree ctas17. The two genes at this locus,
CRYGC and CRYGD, were sequenced in three affected and one unaffected individuals from pedigree ctasl7 (see fig 1). Two variants were detected in exon 2 of CRYGD and screened by dHPLC in the entire pedigree, 100 normal control chromosomes and the proband from each of the other congenital cataract pedigrees. The first mutation was a synonymous $\mathrm{C} \rightarrow \mathrm{T}$ substitution at the third base of codon 16 (Y16) which did not segregate with disease and was present in $25 \%$ of the control chromosomes. The second was a non-synonymous $\mathrm{C} \rightarrow \mathrm{A}$ transversion at the first base of codon 24 (P23T). This mutation segregated with disease in pedigree ctas 17 and was not identified in the control chromosomes or any other proband.

The phenotype in ctas17 was well documented in only a few individuals as the majority of patients had surgery before 3 years of age and no clinical photographs were available. The opacity was a flaky, silica-like nuclear cataract, associated with a poor red reflex. Best corrected visual acuities after surgery varied from 6/6 to no perception of light. Thirteen of the 20 patients with documented visual acuities had at least $6 / 15$ vision in one eye, and two family members met the criteria for legal blindness $(<6 / 60)$. Nystagmus was rare.

\section{SSCP analysis}

Analysis of the proband from each pedigree revealed one causative mutation and four non-segregating polymorphisms (table 2). All mutations identified through SSCP of PEP DNA were subsequently confirmed by direct sequencing of genomic DNA, indicating that the use of PEP DNA did not introduce spurious SSCP positive PCR artefacts.

The $\mathrm{G} \rightarrow \mathrm{A}$ transition detected at the first base of the $5^{\prime}$ donor splice site of intron 3 in the CRYBAI/A3 gene segregated with disease in pedigree crch08, as demonstrated by RFLP analysis (fig 2A). The clinical features of the phakic patients in this Australian family of European origin showed a consistent spectrum of: (1) Y-sutural opacities, (2) mild opacification throughout the region of the fetal nucleus, and (3) peripheral cortical dot opacities (fig $2 \mathrm{~B}$ ). The severity of the disease ranged from requiring surgery in childhood to unawareness of affected status before this study. Individual III:3 of pedigree crch08 is heterozygous for the mutation. Mild opacities consistent with his age (65 years) characterised as nuclear sclerosis with cortical opacities were noted following genotyping revealing his carrier status and could represent a mild form of the inherited phenotype. As this mutation and a second mutation at the same base have been previously shown to segregate with congenital cataract and not found in 150 control chromosomes of various ethnicity, ${ }^{12}{ }^{13}$ population controls from south eastern Australia were not screened. The mutation was not detected in any of the Australian probands. 


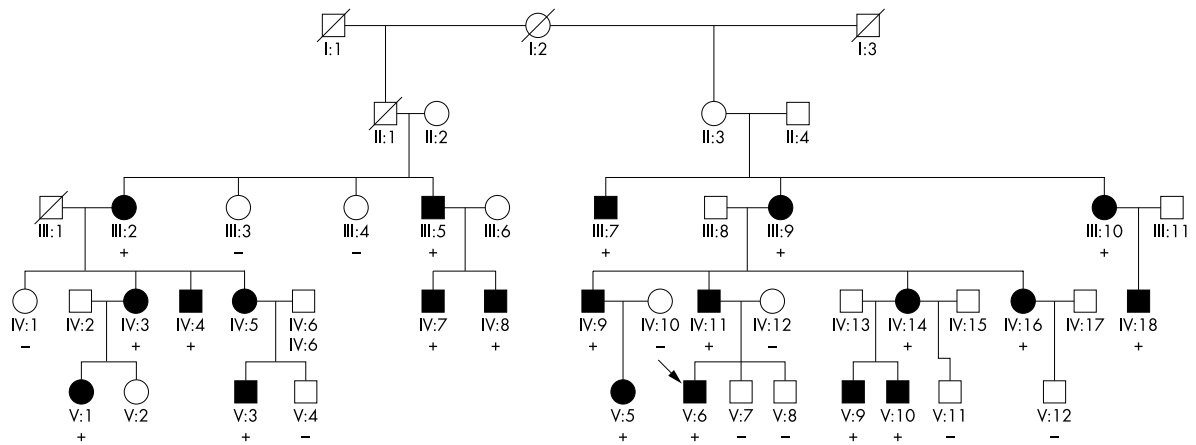

Figure 1 Pedigree of ctas 17 , indicating the presence of the CRYGD P23T mutation. Shaded symbols indicate the presence of ophthalmologist confirmed cataract, and the proband is indicated by an arrow. + indicates a heterozygote; indicates wild type; individuals without $a+$ or - symbol were unavailable for genotyping.

\section{DISCUSSION}

Mutations of crystallin genes represent $45 \%$ of the reported familial cataract mutations to date. We have screened all genes by linkage, and the first five crystallin genes reported to cause cataract by SSCP, and detected two mutations that segregate with the cataract phenotype-CRYGD P23T and a CRYBA1/A3 splice site mutation-as well as five other nondisease causing polymorphisms.

This collection of pedigrees were ascertained through a comprehensive evaluation of almost all familial cataract in south eastern Australia, a source population of around five million, and participation rates were high. ${ }^{21}$ Only those families with inherited cataract where none of the family members required specialist medical care and sporadic cases later shown to be familial would have been overlooked. ${ }^{21}$

Both the mutations detected in this study have been previously reported in other large congenital cataract pedigrees. The P23T mutation of CRYGD has been associated with differing phenotypes including lamellar cataract in an Indian pedigree ${ }^{26}$ and Cerulean cataract in a Moroccan family. ${ }^{27}$ Three other mutations of this gene have also been associated with cataract. ${ }^{16}{ }^{26}$ As the P23T mutation has been found to segregate with congenital cataract in three independent studies and has not been detected in 400 control chromosomes, ${ }^{26}{ }^{27}$ it is unlikely to represent a rare polymorphism. It is unclear how the P23T mutation affects the function of the CRYGD protein. The mutation is located in the second $\beta$ sheet of the first Greek key motif of the protein, a region crucial to the correct folding of the protein. ${ }^{27}$ This residue is a proline or serine in all species represented in Genbank, but never a threonine. The backbone of the native human proline forms a hydrogen bond with Asn49. A threonine at this position maintains this bond but the polar side chain also forms a strong bond with Tyr $50 .{ }^{27}$ This appears to be sufficient to cause disease.

A splice site mutation of CRYBAI/A3 has been associated with pulverulent phenotypes in families from India ${ }^{12}$ and Brazil, $^{13}$ although the Brazilian pedigree had a $\mathrm{G} \rightarrow \mathrm{C}$ transversion, rather than the $\mathrm{G} \rightarrow \mathrm{A}$ transition observed in the Indian and Australian pedigrees. No other mutations of this gene have been reported. Although individual III:3 of crch08 carries the CRYBAI/A3 mutation, it is unclear whether his mild opacity represents expressivity or reduced penetrance in the presence of age related cataract. The mutation is predicted to result in premature termination of the polypeptide $^{12}$ and would affect both the CRYBAl and CRYBA3 proteins as both are translated from the same mRNA. ${ }^{28}$ As with the CRYGD P23T mutation, the presence of mutations of the same base of the CRYBAI/A3 gene segregating with cataract phenotype in three independently investigated pedigrees, and lack of detectable changes in 150 control chromosomes, indicates that this mutation is likely to be causative.

Although the splice site mutation detected in intron 3 of CRYBB2 would be expected to be a functional change it did not segregate with disease. It is likely that this mutation is actually in the CRYBB2 pseudogene which has sequence identity with the translated gene in the region of exon $3 .{ }^{29}$

SSCP is predicted to detect approximately $70-90 \%$ of sequence variants, depending on the conformation of the fragment under investigation. The CRYGD P23T mutation was not detected by SSCP and it is possible that other causative mutations were undetected. However, SSCP was deemed an appropriately rapid and inexpensive method for the initial screen of 19 exons in these pedigrees.

In Australian pedigrees of European ancestry collected through a population based approach, we have detected two causative crystallin mutations, both described previously. ${ }^{12} 132627$ Considering the different ethnic origins of the pedigrees, we speculate that these mutations are likely to have arisen independently. This is only the third report describing cataract mutations common to more than one family, and indicates the critical nature of these residues to the function of the protein in the lens. Mutations of crystallin genes account for 17 of 38 congenital cataract mutation reports in the literature. However the low prevalence of causative mutations in the crystallin genes investigated in this study - with mutations detected in only two of 38 pedigrees-indicates that they are not a common cause of familial cataract in this population.

Table 2 Variants of crystallin genes detected in cataract families

\begin{tabular}{llllll}
\hline Gene & Exon/intron & Position* $^{*}$ & Base change & $\begin{array}{l}\text { Expected effect on } \\
\text { protein }\end{array}$ & $\begin{array}{l}\text { Segregation with } \\
\text { cataract phenotype }\end{array}$ \\
\hline CRYBA1/A3 & Intron 3 & +1 & G/A & Splice Site & Yes \\
CRYBA1/A3 & Exon 5 & Codon 152 & C/T & None (Gly) & No \\
CRYBA1/A3 & Intron 2 & +73 & T/G & None & No \\
CRYBA1/A3 & Intron 3 & +16 & C/T & None & No \\
CRYBB2 $†$ & Intron 3 & +1 & G/A & Splice site & No \\
CRYGD & Exon 2 & Codon 16 & C/T & None (Tyr) & No \\
CRYGD & Exon 2 & Codon 23 & C/A & Pro/Thr & Yes \\
\hline
\end{tabular}

*Intron position numbers refer to the number of nucleotides past the 3 ' end of the exon. †This variant is likely to be in the presumed pseudogene CRYBB2-2, rather than CRYBB2. 
A
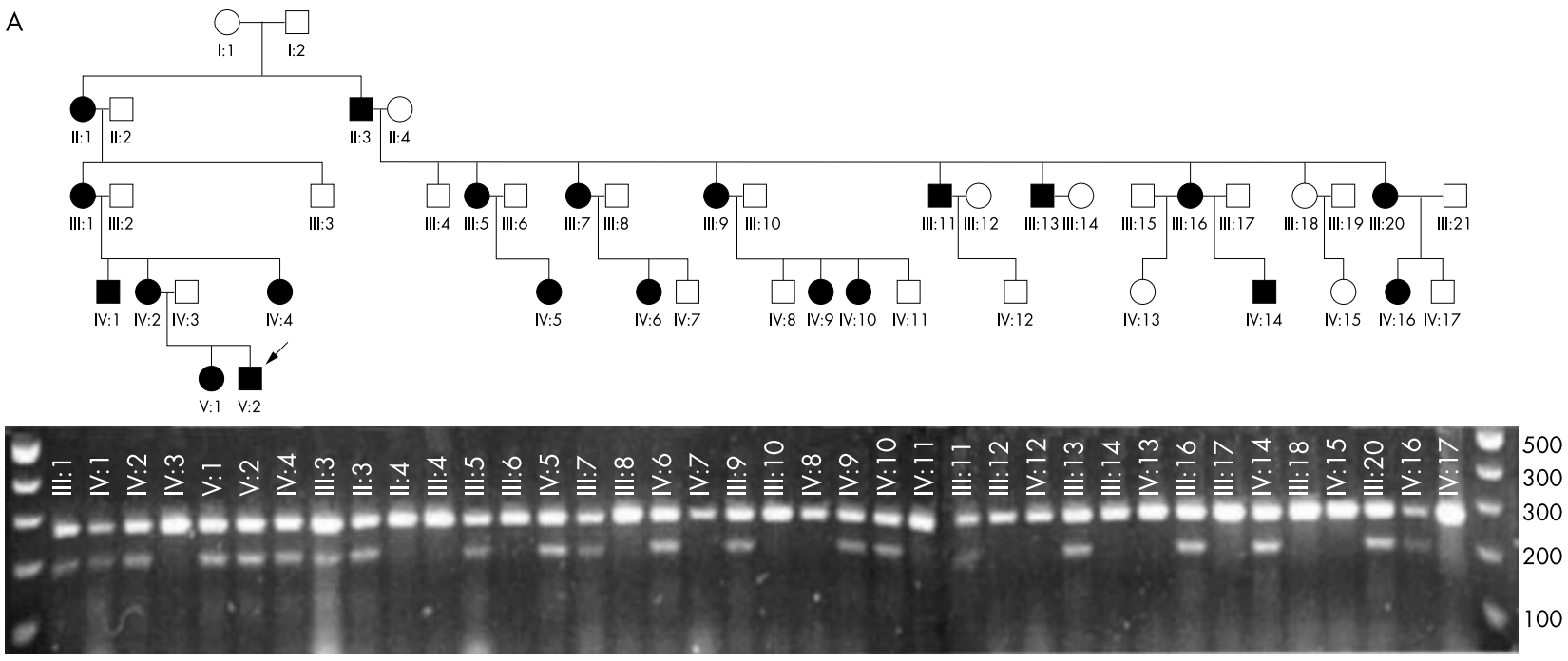

B
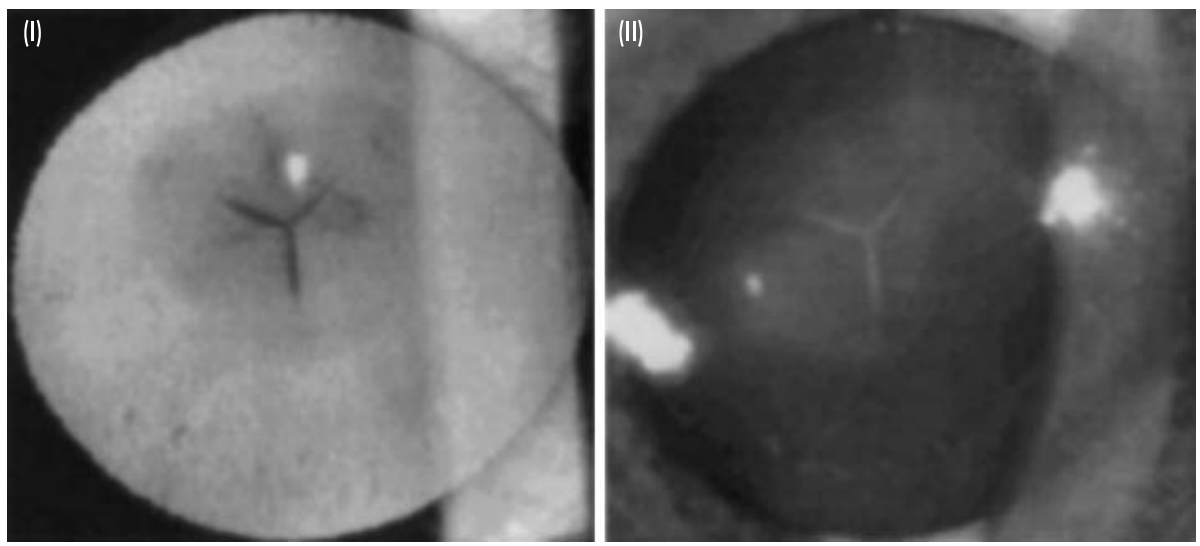

Figure 2 (A) Restriction fragment length polymorphism analysis of the mutation at the donor splice site of exon 3 of the CRYBAI/A3 gene in pedigree crch08. Sizes of fragments in the molecular standard lane are indicated in base pairs (bp). Shaded symbols indicate the presence of ophthalmologist confirmed cataract, and the proband is indicated by an arrow. Wild type individuals display only the 263 bp band. Individuals heterozygous for the mutation display the undigested $263 \mathrm{bp}$ band, as well as $172 \mathrm{bp}$ and $91 \mathrm{bp}$ cleavage products, although the latter band is not clear on the gel. (B) (i) Direct and (ii) retroilluminated pictures of sutural, nuclear, and peripheral cortical opacity typical of an affected patient in this pedigree (III:9). There is considerable intrapedigree variablility of the relative predominance of each component.

\section{ACKNOWLEDGEMENTS}

We wish to thank the families for their participation. Thanks to Susan Stanwix, Mimiwati Zahari, and Danielle Healy for assistance in arranging ophthalmic examinations and DNA collection, Andrew Bell and Michele Brown for technical assistance, and Adrian West for helpful comments on the manuscript. Jamie Craig is supported in part by an NHMRC practitioner fellowship. Grant support for this project was received from the Ophthalmic Research Institute of Australia, the Jack Brockhoff Foundation, and the Royal Hobart Hospital Research Foundation. The Menzies Centre for Population Health Research Genetic Epidemiology Unit received financial support from Cerylid Biosciences.

\section{Authors' affiliations}

K P Burdon, J L Dickinson, M M Sale, Menzies Centre for Population Health Research, University of Tasmania, Hobart, Australia M G Wirth, Department of Ophthalmology, University of Zürich, Switzerland

D A Mackey, J E Craig, Centre for Eye Research Australia, University of Melbourne, Royal Victorian Eye and Ear Hospital, Melbourne, Australia I M Russell-Eggitt, Great Ormond Street Hospital for Children, London, UK

J E Craig, Department of Ophthalmology, Flinders University, Adelaide, Australia

J E Elder, Department of Ophthalmology, Royal Children's Hospital,
Melbourne, Australia

M M Sale, Center for Human Genomics and Department of Internal Medicine, Wake Forest University School of Medicine, Winston-Salem, USA

\section{REFERENCES}

1 lonides A, Francis $\mathrm{P}$, Berry $\mathrm{V}$, et al. Clinical and genetic heterogeneity in autosomal dominant cataract. Br J Ophthalmol 1999:83:802-8.

2 Kramer PL, LaMorticella D, Schilling K, et al. A new locus for autosomal dominant congenital cataracts maps to chromosome 3. Invest Ophthalmol Vis Sci 2000;41:36-9.

3 Francis PJ, Berry V, Moore AT, et al. Lens biology: development and human cataractogenesis. Trends Genet 1999;15:191-6.

4 Berry V, Francis P, Kaushal S, et al. Missense mutations in MIP underlie autosomal dominant 'polymorphic' and lamellar cataracts linked to 12q. Nat Genet 2000:25:15-17.

5 Pras E, Levy-Nissenbaum E, Bakhan T, et al. A missense mutation in the LIM2 gene is associated with autosomal recessive presenile cataract in an inbred Iraqi Jewish family. Am J Hum Genet 2002;70:1363-7.

6 Conley YP, Erturk D, Keverline A, et al. A Juvenile-onset, progressive cataract locus on chromosome $3 q 21-q 22$ is associated with a missense mutation in the beaded filament structural protein-2. Am J Hum Genet 2000;66:1426-31.

7 Jakobs PM, Hess JF, Fitzgerald PG, et al. Autosomal-dominant congenital cataract associated with a deletion mutation in the human beaded filament protein gene BFSP2. Am J Hum Genet 2000;66:1432-6.

8 Semina EV, Ferrell RE, Mintz-Hittner HA, et al. A novel homeobox gene PITX3 is mutated in families with autosomal-dominant cataracts and ASMD. Nat Genet 1998;19:167-70. 
9 Bu L, Jin Y, Shi Y, et al. Mutant DNA-binding domain of HSF4 is associated with autosomal dominant lamellar and Marner cataract. Nat Genet 2002;31:276-8

10 Litt M, Kramer P, LaMorticella D, et al. Autosomal dominant congenital cataract associated with a missense mutation in the human alpha crystallin gene CRYAA. Hum Mol Genet 1998;7:471-4.

11 Pras E, Frydman M, Levy-Nissenbaum E, et al. A nonsense mutation (W9X) in CRYAA causes autosomal recessive cataract in an inbred Jewish Persian family. Invest Ophthalmol Vis Sci 2000:41:3511-5.

12 Kannabiran C, Rogan PK, Olmos L, et al. Autosomal dominant zonular cataract with sutural opacities is associated with a splice mutation in the betaA3/A1-crystallin gene. Mol Vis 1998;4:21.

13 Bateman JB, Geyer DD, Flodman P, et al. A new betaA 1 -crystallin splice junction mutation in autosomal dominant cataract. Invest Ophthalmol Vis Sci 2000;41:3278-85.

14 Litt M, Carrero-Valenzuela R, LaMorticella DM, et al. Autosomal dominant cerulean cataract is associated with a chain termination mutation in the human beta-crystallin gene CRYBB2. Hum Mol Genet 1997;6:665-8.

15 Gill D, Klose R, Munier FL, et al. Genetic heterogeneity of the Coppock-like cataract: a mutation in CRYBB2 on chromosome 22q11.2. Invest Ophthalmol Vis Sci 2000;41:159-65.

16 Heon E, Priston M, Schorderet DF, et al. The gamma-crystallins and human cataracts: a puzzle made clearer. Am J Hum Genet 1999;65:1261-7.

17 Ren Z, Li A, Shastry BS, et al. A 5-base insertion in the gammaC-crystallin gene is associated with autosomal dominant variable zonular pulverulent cataract. Hum Genet 2000;106:531-7.

18 Stephan DA, Gillanders E, Vanderveen D, et al. Progressive juvenile-onset punctate cataracts caused by mutation of the gammaD-crystallin gene. Proc Natl Acad Sci USA 1999;96:1008-12.
19 Berry V, Francis $P$, Reddy MA, et al. Alpha-B crystallin gene (CRYAB) mutation causes dominant congenital posterior polar cataract in humans. Am J Hum Genet 2001;69:1141-5.

20 Mackay DS, Boskovska OB, Knopf HL, et al. A nonsense mutation in CRYBB associated with autosomal dominant cataract linked to human chromosome 22q. Am J Hum Genet 2002;71:1216-21.

21 Wirth MG, Russell-Eggitt IM, Craig JE, et al. Aetiology of congenital and paediatric cataract in an Australian population. $\mathrm{Br} J$ Ophthalmol 2002;86:782-6.

22 Zhang L, Cui X, Schmitt K, et al. Whole genome amplification from a single cell: Implications for genetic analysis. Proc Natl Acad Sci 1992;89:5847-51.

23 Cottingham RW Jr, Idury RM, Schaffer AA. Faster sequential genetic linkage computations. Am J Hum Genet 1993;53:252-63.

$24 \mathrm{OH} \mathrm{J}$. Computer-simulation methods in human linkage analysis. Proc Nat Acad Sci USA 1989;86:4175-8.

25 Weeks DE, OH J, Lathrop GM. SLINK: a general simulation program for linkage analysis. Am J Hum Genet 1990;47(Suppl):A204.

26 Santhiya ST, Shyam Manohar M, Rawlley D, et al. Novel mutations in the gamma-crystallin genes cause autosomal dominant congenital cataracts. J Med Genet 2002;39:352-8.

27 Nandrot E, Slingsby C, Basak A, et al. Gamma-D crystallin gene (CRYGD) mutation causes autosomal dominant congenital cerulean cataracts. J Med Genet 2003;40:262-7.

28 Werten PJ, Carver JA, Jaenicke $\mathrm{R}$, et al. The elusive role of the $\mathrm{N}$-terminal extension of beta A3- and beta A1-crystallin. Protein Eng 1996;9:1021-8.

29 Brakenhoff RH, Aarts HJ, Schuren F, et al. The second human beta B2 crystallin gene is a pseudogene. Exp Eye Res 1992;54:803-6.

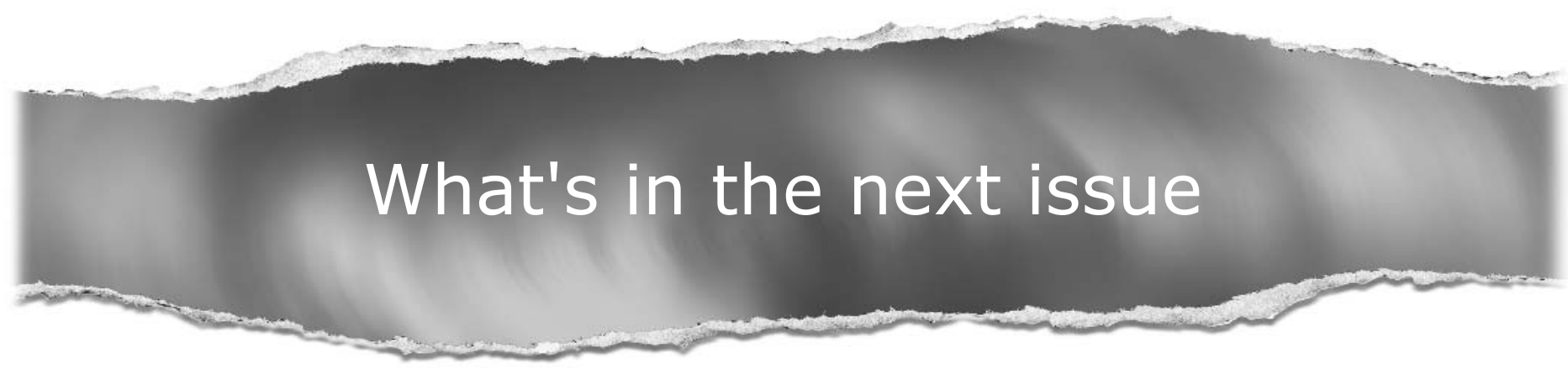

\section{Future content}

See which articles have just been accepted for publication and preview the table of contents for the next issue a month before it is published

\section{www.bjophthalmol.com}

